\title{
Leprosy Masquerading as Tinea Faciale
}

\author{
Manju Daroach ${ }^{1}$ Hitesh Bhallavi $^{1}$ Tarun Narang $^{1}$ \\ ${ }^{1}$ Department of Dermatology, Venereology and Leprology, \\ Postgraduate Institute of Medical Education and Research, \\ Chandigarh, Punjab, India
}

Ann Natl Acad Med Sci (India) 2022;58:50-51.

A male in his 40s presented to the dermatology department of Post Graduate Institute of Medical Education and Research, Chandigarh, in December 2019 with a non-pruritic, large annular plaque of size $20 \times 25 \mathrm{~cm}$ over face for 6 months (-Fig. 1A-C). He had been treated for tinea faciale for $\sim 3$ to 4 months, with no improvement. On examination, a well-defined annular plaque with elevated erythematous border and scaling was observed. There was appendageal loss overlying the lesion, but no regional or peripheral nerve thickening was observed. Potassium hydroxide examination and slit skin smear were negative. Histopathological examination showed epithelioid cell granulomas with peripheral lymphocytes in the dermis along the nerve bundles and Langhans giant cells; however,
Address for correspondence Tarun Narang, MD, DNB, MNAMS, Department of Dermatology, Venereology and Leprology, Postgraduate Institute of Medical Education and Research, Sector 12 , Chandigarh 160012, Punjab, India (e-mail: Narangtarun@yahoo.co.in).

no acid-fast bacilli were seen ( $\mathbf{F i g}$. 2A, B). He was diagnosed with borderline tuberculoid Hansen and was prescribed WHO multidrug therapy multibacillary regimen with monthly follow-ups, leading to complete resolution of the lesion. Leprosy can have a polymorphous presentation and there are reports of leprosy lesions mimicking psoriasis, pityriasis versicolor, granuloma annulare, leishmaniasis, sarcoidosis, syphilis, and vitiligo. Both leprosy and tinea faciale may present as annular lesions and at times it is difficult to differentiate between the two clinically. The differentiating features that help in diagnosis are tinea faciale lesions which are annular, pruritic, with preserved appendages and sensations. Whereas the lesions of borderline tuberculoid leprosy are non-pruritic/

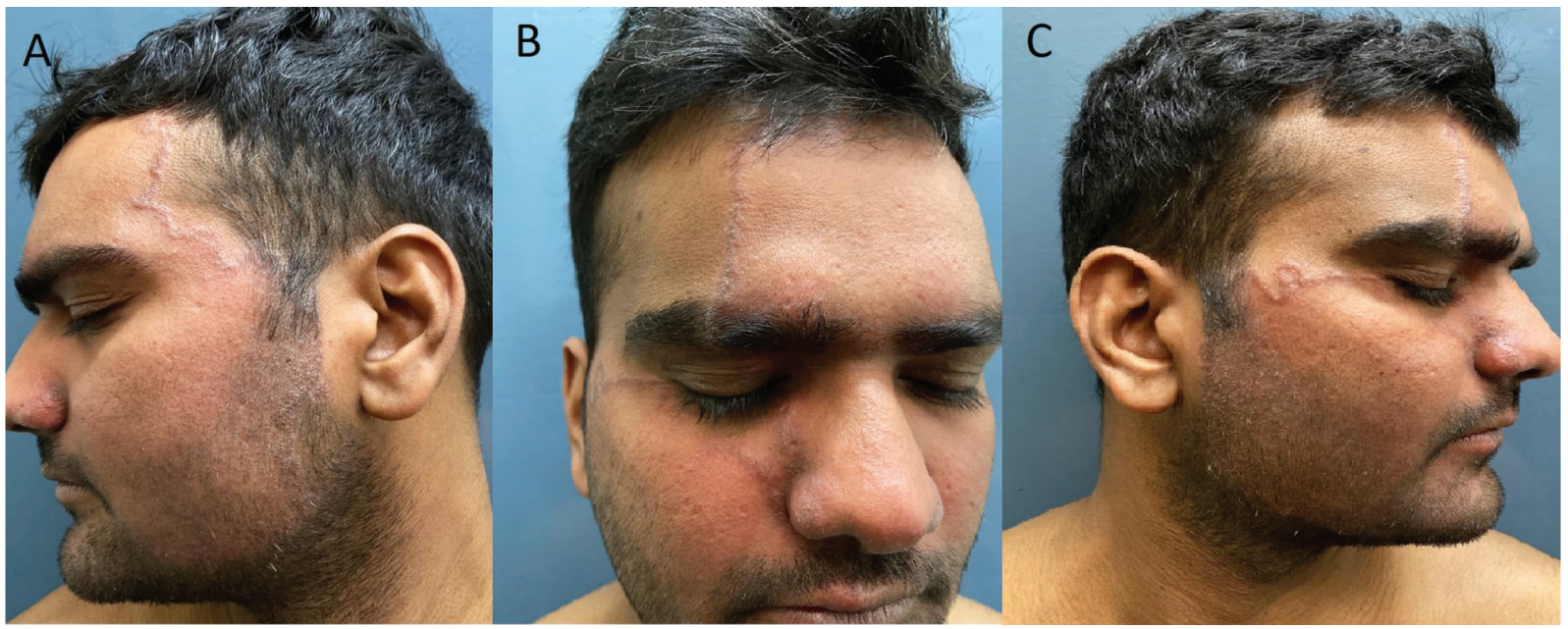

Fig. 1 Well-defined erythematous annular plaque with mild scaling on the left lateral side of the face (A); anterior side of the face (B); and lesion on the right lateral side of the face (C).

published online

November 10, 2021
DOI https://doi.org/

$10.1055 / \mathrm{s}-0041-1736508$ ISSN 0379-038X. (c) 2021. National Academy of Medical Sciences (India). All rights reserved.

This is an open access article published by Thieme under the terms of the Creative Commons Attribution-NonDerivative-NonCommercial-License, permitting copying and reproduction so long as the original work is given appropriate credit. Contents may not be used for commercial purposes, or adapted, remixed, transformed or built upon. (https://creativecommons.org/ licenses/by-nc-nd/4.0/)

Thieme Medical and Scientific Publishers Pvt. Ltd., A-12, 2nd Floor, Sector 2, Noida-201301 UP, India 


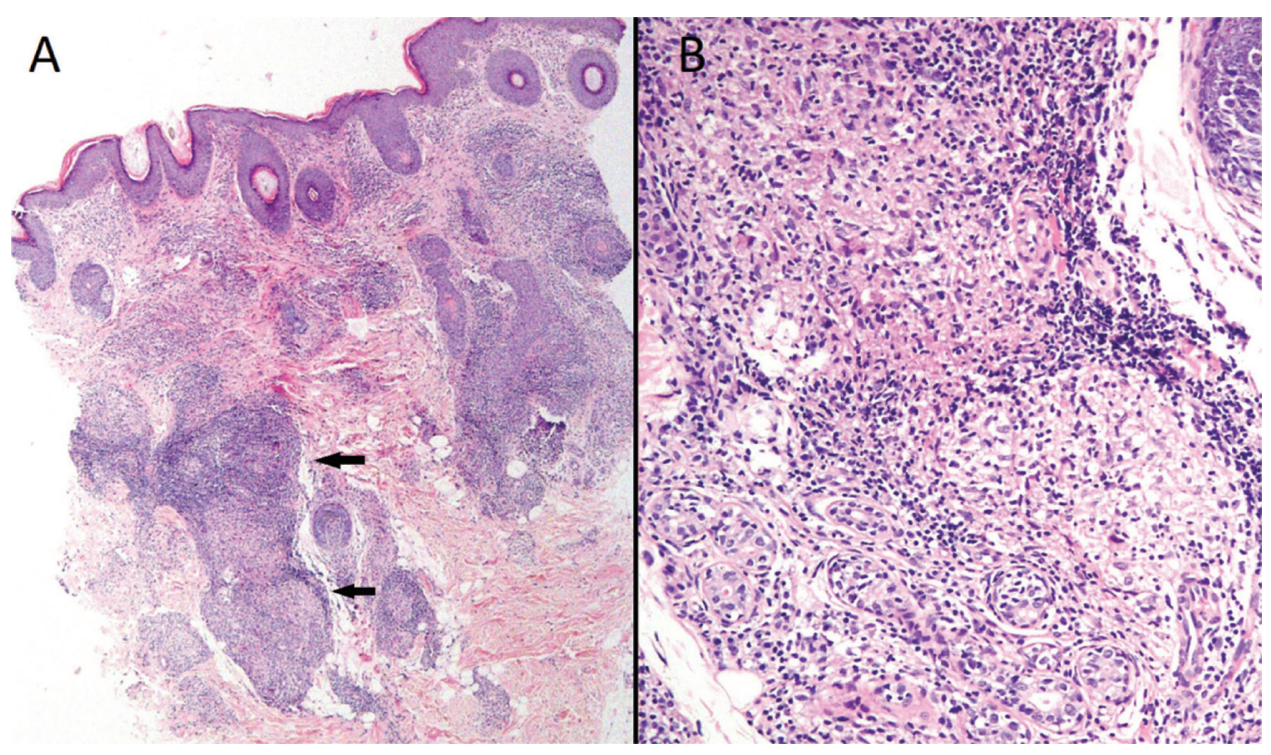

Fig. 2 Histopathology showing multiple well-circumscribed epithelioid cell granulomas in perivascular and periadnexal locations in the dermis (black arrow). (A and B) (A: hematoxylin and eosin 40x, B: hematoxylin and eosin 200x;).

asymptomatic, hypopigmented, or erythematous plaques (more infiltrated), with loss of appendages and regional/ peripheral nerve thickening. With the current epidemiclike situation of dermatophytosis, awareness regarding these atypical presentations is important in countries where leprosy is still prevalent for early diagnosis and treatment to prevent disabilities.

\section{Conflict of Interest}

None declared.

\section{Acknowledgment}

We acknowledge the help of Dr. BD Radotra and Dr. Divya Aggarwal (Department of Histopathology, PGIMER, Chandigarh) for advice in interpreting the histopathological image. 